\title{
Setting up a fee-based information service in an academic library
}

\author{
Claudette Cloutier, B.Sc., MLIS \\ Manager, Gallagher Library of Geology and Geophyiscs \\ University of Calgary \\ 2500 University Drive N.W. \\ Calgary, AB Canada T2N 1N4 \\ ccloutie@ucalgary.ca
}

Revision submitted to Journal of Academic Librarianship

November 22, 2004 


\section{$\underline{\text { ABSTRACT }}$}

In response to local demand, the University of Calgary Library established a fee-based information service for non-university clientele. The benefits from this service have been intangible and financial. This article reviews the planning and implementation of the service and its future directions.

\section{INTRODUCTION}

The motive for setting up a fee-based information service in an academic library is to provide access to information services regardless of client group and to enhance public relations between the university and the community. There will be a financial cost to setting up a fee-based information service, but the benefits of offering such a service far outweigh the risks. Because of this, the primary motive should not be about generating a profit but gaining on intangibles. Through a fee-based information service, the library has the potential of boost its image within the institution and within the community at large, increasing opportunities for improved collection development via donors, and forming new and significant partnerships with the business community ${ }^{[1,2]}$. Operational costs such as promotion, staffing and service delivery are counterbalanced by the advantages gained. The University of Calgary Library's practical approach to setting up its' own fee-based service is based on this premise.

\section{WHY SET UP A FEE-BASED SERVICE?}

The University of Calgary Library's Corporate Research Service was set up four years ago in response to decreased funding support and growing demands from external users placed on the collections and services of one of its branch libraries, the Gallagher Library of Geology and Geophysics (Gallagher Library). Prior to 1999, the University Library received funding contributions from the Department of Geology and Geophysics to support the operation of the Gallagher Library. Due to budget constraints within the institution this funding was terminated and resulted in decreased hours of operation primarily on evenings and weekends. At the same time within Calgary, a number of corporate offices in the petroleum industry downsized and their 
libraries were closed. Staff were directed to the University for their research needs. The Gallagher Library noted an immediate increase in walk-in users as well as an increase in telephone and email information requests by non-university clientele. This increase in demand upon staff, by non-university clientele, resulted in a reduction of time available to our primary client group, the faculty, staff and students of the University. A resolution was needed.

The Gallagher Library has one of the premier geology collections in Western Canada. The collection's strengths include regional, structural and petroleum geology, geophysics, geochemistry, sedimentology and paleontology, with particular emphasis on the Western Canada Sedimentary Basin. The library is also one of the few local collections of materials related to the petroleum industry which is open to the public. The other three collections are in libraries affiliated with government departments at both the provincial and federal level with limited access. The need was there and the Gallagher Library's collection was strong; however, other elements were equally important in making the decision to develop a targeted, more comprehensive feebased service.

First, although the University Library did offer a limited fee-based information services on an ad hoc basis, it was not robust enough to handle the increase in requests and complex service requirements of non-university clientele. It was sporadic and unreliable. Services could include online searching and document delivery from within the University Library's collections. However, online searches were only conducted if the responding subject librarian had the time or search expertise and document delivery services were only provided to corporate clients with libraries. Another solution was needed. In reviewing the situation, it was clear that using the Gallagher Library and its staff to implement a Corporate Research Service, directed specifically at those clients who most wanted to use the associated resources had many advantages. Gallagher Library staff brought with them a tremendous amount of experience and knowledge of petroleum related materials. Additionally, extensive industry contacts formed over 20 years of providing service to faculty, students and alumni meant that a sound foundation for initiating a contact list 
was present. Finally, the current Manager of the Gallagher Library had previous experience with fee-based services at other institutions and was knowledgeable about details in operating and delivering such a service. These factors, plus collection strength meant the Gallagher Library was uniquely positioned to develop a fee-based service.

\section{DEVELOPING A PROPOSAL FOR A FEE-BASED SERVICE}

Once the need for a fee-based service had been identified, a proposal was developed and presented to library management. It was emphasized that the service would provide the petroleum industry with one stop access to the research experience and information they required. While this went beyond the current service philosophy of the University Library, it was seen as a way to attract funding support from those who were already using the collection.

The proposal outlined the current situation and examined the existing environment. A number of fee-based services, both local and international were benchmarked to determine the range of services to offer, fee structure, as well as the operation and management of the service. These services included the local public library's Business Information Service, CISTI, Petroleum Abstracts, Linda Hall Library of Science, Engineering and Technology, Purdue University Libraries' Technical Information Service, and the University of California at San Diego's Plus service. Great care was taken to avoid duplicating local services or competing with private local information brokers. Throughout the process it was necessary to develop the service within an institutional context, such as working with established service descriptions and pricing models.

Based on experience and client requests, the services that were proposed focused on two areas: research services and document delivery services. Research services were defined as the mediated use of online commercial databases, the Internet or other research collections by library staff in response to an information request. Document delivery services included the delivery of articles, books, reports, theses or other publicly available materials whether they were available in the local collection or not. 
Once the services had been set, a pricing model and mechanism for tracking costs were established. Based on information collected from the benchmarked services and existing institutional fees, prices were set for professional research time, local interlibrary loan, local document copying, external interlibrary loan, and external document copying. These prices were competitive with other services and took into account the true costs of the services, including verification of citation information, copyright charges, photocopying, taxes and tariffs and the staff time required to fill requests. Licensing restrictions of the library's locally subscribed online databases were also considered. As with any large academic institution, the University of Calgary Library subscribes to a large number of databases at an institutional rate. The cost of setting up commercial accounts through Dialog, subscriber accounts for Petroleum Abstracts and commercial document delivery accounts with a number of vendors was factored into the proposal. Lastly, a number of commercial information management products were explored before it was finally determined to create an in-house tracking system using Microsoft Access. The existing software products were traditional interlibrary loan management systems and could not be easily customized to reflect the variety of service requests that were anticipated.

There were also legal and tax arrangements that had to be considered. In Canada, there is a Goods and Services Tax (GST) charged on all services. As the Library was providing a service, it needed to factor this tax into its invoicing procedures. This 7\% tax is charged on all services except on the annual subscription fee. In addition most not for profit organizations are GST exempt, so separate invoicing reports were created in anticipation of this. The library's financial services group handles the collection and distribution of the revenue and GST. Copyright fees also had to be included in the pricing of document copying. These fees are collected quarterly and dispersed to the Access Copyright office as required by legislation. Finally, a statement of liability was drafted to be included on all outgoing searches and contracts. 
The service was structured so that it could be conducted by existing reference staff in the Gallagher Library with student assistants providing support for verification of document delivery requests, photocopying, report formatting and data entry. Most of the tasks required by a feebased service are routine and can be performed by anyone with limited training. The use of student assistants for these tasks would free up the time of the reference staff to deal with the more complex information requests, and to concentrate on service to their primary clientele. Further, it was anticipated that with the fees coming in from the service, student hours could be increased or extra students hired This would allow for increased support for the Corporate Research Service as well as a return to previous service levels through reinstatement of evenings and weekend hours. Assistance was also required from the library's financial services group and Access Services unit to handle invoicing and tracking of vendor payments. This support was negotiated before the proposal was approved. Finally to ensure that the service was operationally viable, it would be reviewed annually. Library management approved the proposal.

\section{IMPLEMENTING THE UNIVERSITY OF CALGARY LIBRARY'S FEE-BASED SERVICE}

Once the proposal was approved, the task of implementing began. First, a services contract was developed that outlined a three tier subscription model and the services to be offered at each level. A copy of the contract is included at the end of this article. It was determined that this type of model would attract a variety of clientele. The top level service model was targeted at large oil and gas companies (more than 1,500 employees) who no longer had internal libraries. With this model, clients pay an annual fee of $\$ 10,000$ which exempts them from additional fees for professional research time, their first 100 article requests and local interlibrary loan. Other services are charged back at the current rate. These clients also receive 15 library cards for use by their employees. The middle tier provides a more modest service. It is targeted at small to medium organizations that would likely submit a modest amount of requests per year, but still use the service quite heavily. They pay a discounted rate for professional time and do not pay for local interlibrary loan. All other services are charged back at the current rate. The lowest subscription level is $\$ 150.00$ annually and is targeted at small organizations or independent 
consultants. The annual fee covers administrative costs and clients pay the current rate for all service requests.

To implement the service, all non-university clientele past and present known to the library were contacted regarding the proposed service plan. As there were four major oil and gas conferences being held in Calgary at the time, staff from the Library attended these events to solicit more clients. Finally the major oil and gas companies that had closed their libraries were contacted about the service and contracts were negotiated with two of the organizations. Staff who worked at public access points within the University Library were asked to refer anyone they felt might benefit from such a service. In all cases, subscribers were satisfied to have to have the library offer such a service.

Other than these planned events there was very little emphasis on marketing the service. A web link off the main page of the Gallagher Library explaining and promoting the service is provided and all interested parties are sent a copy of the services contract. The service relies heavily on word of mouth and industry contacts made through other means to attract new clients. To date, extensive marketing has not been required to sustain the client base or encourage new growth. Once a client base was established, the requests began to come in. Contracts with external document suppliers and online search services were set up as required. A summer student using feedback provided to him by staff, created a database in Microsoft Access that tracked all of the requests by client and type and generated quarterly invoices and reports as required. The invoices were sent to the Library's financial services group for billing purposes. It was a successful beginning that has continued to develop.

At the time of writing, the University of Calgary Library Corporate Research Service is in its fourth year of operation. The client base remains steady at about 55 clients registered annually with 2 at the top service level and the remainder at the pay per use level. Client turnover is generally due to mergers and acquisitions within the industry. To date over 3,000 item requests have been 
processed. Eighty percent of the requests are for document delivery and interlibrary loan, twelve percent of the requests are for research or online searches and less than ten percent of the requests are cancelled because the item requested is not available for lending or copying. There are fluctuations in the number of requests filled in any given year, but this is generally attributable to the volatility in the oil and gas industry. In essence, the service functions smoothly and has resulted in several of the expected benefits. The service generates a modest amount of revenue that is used to pay for student assistant hours and for collection enhancements. The image of the Gallagher Library and indeed of the University of Calgary has been enhanced within the business community through the services that are offered. Individuals who are familiar with the service have become involved in Library fundraising initiatives. The Gallagher Library is also viewed as a favorable destination for collection donations from retiring geologists and geophysicists and from organizations who are downsizing their on site library collections.

\section{COSTS FOR OPERATING THE SERVICE}

There has been very little change in the annual budget process over the last four years of operating the University of Calgary Library Corporate Research Service as demand has remained steady. On average the up front subscription fees generate about $\$ 20,000 \mathrm{CDN}$. Services are charged back on a cost recovery basis, so while approximately $\$ 15,000$ CDN is invoiced annually for services, most of this revenue goes towards covering payments to external vendors, copyright tariff charges, and staffing costs for student assistants. Additional costs such as those incurred through equipment use, training, supplies and materials are absorbed as part of the normal Gallagher Library budget. Further by bundling the Corporate Research Service into the duties of two regular full-time permanent positions, a librarian and a para-professional, the University Library is able to run the Corporate Research Service as part of its regular operations and the time committed while not minimal is acceptable.

Approximately $10 \%$ of the professional librarian's time is committed to overseeing the operation of the service. This includes the annual budgeting and report process, ongoing client 
management, client renewals, and online searching and request verification as required. About $20 \%$ of the para-professional's time is committed to overseeing the day to day operations of the service including monthly and quarterly service reports, delegating tasks to the student assistants, verifying requests before they are sent to the client, and online searching and verification as required. Student assistants after some training, code the requests, enter the data and prepare the requests for shipping. They are paid for out of the Library's budget and by revenue from the Corporate Research Service. As stated at the beginning, the primary goals of the Corporate Research Service were to generate a modest amount of revenue to make up for the Library's loss of financial support from the Department of Geology and Geophysics and to foster awareness and research relationships within the business community and with potential donors. The Corporate Research Service as it is currently structured meets these goals very well.

\section{CONCLUSION}

The first years of the University of Calgary Library's fee-based service have been about setting up the service and establishing processes and procedures. The next few years may see a number of changes. As prices have not changed in the past four years, the pricing structure needs to be re-examined. The base price for professional time is low given current market rates and the base subscription price could also be increased given current market rates. Expansion of the service to clients in other industries is also a consideration. At some point, as the service continues to evolve, it is anticipated that the service desk will move out of the Gallagher Library and into the main library, positioning it more centrally to other library services. A move such as this would require a new and more comprehensive business plan with a sound marketing strategy. In addition, the Library would need to review staffing and other infrastructure support used to offer the service for its continued long-term viability.

Instituting the Corporate Research Services was challenging. A number of lessons were learned throughout the process. Clarity with regard to service expectations is crucial both for library staff 
offering the service and clients accessing it. In the case of the Corporate Research Service, the service is considered an extension of what is already being offered by the library to its existing clientele and therefore, not an increase in responsibility or duties. A guiding principle such as this must be acceptable to all parties and fit within contractual agreements or performance standards that define work and expectations.

Client expectations also may be problematic. While the service contract is quite explicit in what the service can and cannot provide, clients continue to surprise staff. For example, some clients don't understand that they cannot access academic database subscriptions from offsite as that is not part of their contract. In other instances, timelines for delivery of results have to be negotiated if a request is complex or the required material is not readily available. Meeting client expectations, while operating within system parameters and constraints, is challenging. Most clients are reasonable and understanding, however, staff must be very good at both negotiation and at keeping them informed. Clients may also expect that because a service is run out of a particular location such as a branch library that the revenue generated by that service goes directly back to unit supporting the service. They may not accept or understand that this is a University service operated out of a particular location. More marketing has to be conducted to change this perception.

Administrative issues are equally challenging. The Corporate Research Service as it was set up has two renewal periods, one in January and one in June. This information is tracked in the inhouse tracking system; however, no provisions were made initially to take into account late renewals. A new client can subscribe to the service at any point during the year but the renewal date, depending on when the subscription is received, is fixed for either January or June. Efforts are made to explain that the subscription fee will cover the period to the renewal date whether it is for a full year or not. Some clients choose to renew only on the anniversary of the date that they first subscribed, while others have 90 day payment terms which can result in payments arriving two months after the renewal date. For a time, renewal on the subscription anniversary was tried, 
however, this resulted in more work for staff. Work on this is ongoing and staff have to continually update this information so that it is readily available at renewal time.

Finally, service growth to the extent that occurred was not anticipated. The current service has saturated the resources of the library staff operating it. If future marketing efforts are successful then the structure and the location of the service will need to be reexamined.

The University of Calgary Library took advantage of a local opportunity when it set up the Corporate Research Service and it has proven to be beneficial. The revenue generated has allowed one of its branches, the Gallagher Library, to normalize its hours of operation and to hire additional student assistants. The library and the institution's image are enhanced within the community and non-university clientele can access important local research collections.

\section{REFERENCES}

1. Ward, S.M., Starting and Managing Fee-Based Information Services in Academic Libraries. (Greenwich: JAI Press Inc, 1997), p. 224.

2. Caren, L. and A. Somerville, Issues facing private academic libraries considering fee-based programs. Reference Librarian 22 (1988): 37-49. 


\title{
GALLAGHER LIBRARY OF GEOLOGY AND GEOPHYSICS CORPORATE RESEARCH SERVICES AGREEMENT
}

\author{
Company Name: \\ Contact Person: \\ Address:
}

\section{RESEARCH SERVICES FOR THE FOR-PROFIT SECTOR 2003}

Terms of Agreement effective for a one-year period beginning:

Research services and supplementary interlibrary loan services/document delivery services through the University of Calgary Library (Gallagher Library) Corporate Research Services are available to participants in this agreement according to the terms set out in the following and upon payment of an annual fee:

\section{SERVICE LEVELS/REGISTRATION FEE}

Participants are to select the level of service they wish to receive. Please note, the annual administration fee does not include online database costs and materials requested from outside of the University of Calgary Library collection. Please refer to the Schedule of Service Charges (page 2).

LEVEL 3

Annual general administration and service fee (to be paid in advance; non refundable)

$\$ 150.00$

Payment of this fee gives the organisation access to research services and interlibrary loan/document delivery services as well as:

$>$ One community reader borrower's card to one designated individual or department

$>$ Sample fax request form, online web ordering form

$>$ Recall privileges

$>$ Research time charged back at $\$ 60.00 /$ hour

$>$ Access via interlibrary loan and document delivery to materials held outside of the University of Calgary collection

LEVEL 2

Annual general administration and service fee (to be paid in advance; non refundable)

$\$ 3,000.00$

Payment of this fee gives the organisation access to research services and interlibrary loan/document delivery services as well as:

$>$ Five community reader borrower's card to 5 designated individuals or departments

$>$ Sample fax request form, online web ordering form

$>$ Recall privileges

$>$ Research time charged back at $\$ 30.00 /$ hour

$>\quad$ No charge for books held in the University of Calgary collection

$>$ Access via interlibrary loan and document delivery to materials held outside of the University of Calgary collection

LEVEL 1

Annual general administration and service fee (to be paid in advance; non refundable)

$\$ 10,000.00$

Payment of this fee gives the organisation access to research services and interlibrary loan/document delivery services as well as:

Fifteen community reader borrower's card to 15 designated individuals or departments

Sample fax request form, online web ordering form

$>$ Recall privileges

$>\quad$ No charge for research time

$>$ First 100 articles free of charge (material held by University of Calgary Libraries only)

$>\quad$ No charge for books held in the University of Calgary collection

$>$ Access via interlibrary loan and document delivery to materials held outside of the University of Calgary collection 
SCHEDULE OF SERVICE CHARGES (GST included):

\begin{tabular}{|c|c|}
\hline $\begin{array}{l}\text { Online Searching } \\
\text { (Research (hourly rate) + database } \\
\left.\text { costs }^{\star *}\right)\end{array}$ & $\begin{array}{l}\text { Level } 1 \text { - No charge for research time }+ \text { database costs } \\
\text { Level } 2-\$ 30.00 / \text { hour }+ \text { database costs } \\
\text { Level } 3-\$ 60.00 / \text { hour }+ \text { database costs }\end{array}$ \\
\hline $\begin{array}{l}\text { Loans (for material within the } \\
\text { University of Calgary Library }\end{array}$ & $\begin{array}{l}\text { Level } 1-\mathrm{N} / \mathrm{C} \\
\text { Level } 2-\mathrm{N} / \mathrm{C} \\
\text { Level } 3-\$ 10.00 \text { per filled request }\end{array}$ \\
\hline $\begin{array}{l}\text { Loans (for material not at the } \\
\text { University of Calgary) }\end{array}$ & $\begin{array}{c}\text { Level } 1,2 \text {, and } 3- \\
\text { point of lending }\end{array}$ \\
\hline $\begin{array}{l}\text { *Photocopies (for material within the } \\
\text { University of Calgary Library) }\end{array}$ & $\begin{array}{l}\text { Level } 1 \text { - first } 100 \text { articles free, for all subsequent requests, } \$ 25.00 \text { flat } \\
\text { fee for first } 50 \text { pages or portion thereof plus } \$ 15.00 \text { for each } \\
\text { additional } 50 \text { pages or portion thereof } \\
\text { Level } 2 \text { - } \$ 25.00 \text { flat fee for first } 50 \text { pages or portion thereof plus } \$ 15.00 \\
\text { for each additional } 50 \text { pages or portion thereof } \\
\text { Level } 3 \text { - } \$ 25.00 \text { flat fee for first } 50 \text { pages or portion thereof plus } \$ 15.00 \\
\text { for each addition } 50 \text { pages or portion thereof }\end{array}$ \\
\hline $\begin{array}{l}\text { *Photocopies (for material not held by } \\
\text { the University of Calgary) }\end{array}$ & $\begin{array}{c}\text { Level } 1,2 \text { and } 3-\$ 30.00 \text { to } \$ 50.00 \text { per filled request, depending on the } \\
\text { point of origin }\end{array}$ \\
\hline Rush Request & Level 1,2 and $3-\$ 20.00$ per filled request in addition to regular charges \\
\hline
\end{tabular}

${ }^{\star *}$ Charges for online searches vary depending on the amount of information retrieved. Costs vary from $\$ 75.00$ upwards.

*University of Calgary Library supplies documents under a negotiated CANCOPY agreement with the understanding that supplied documents are for individual research purposes and not for further resale or redistribution. When documents are supplied to any persons or entities other than non-profit educational institutions, libraries, archives or museums, the University of Calgary Library must pay a tariff to CANCOPY. This tariff is included in the above schedule of service charges.

\section{RUSH SERVICE REQUESTS}

Rush service requests are normally limited to 3 requests per day per Library during busy periods. All rush orders will be filled or cancelled on the same day. (Rush requests must be received by 10:00 a.m. for same day service. As part of the service, Document Delivery Services staff will call individual libraries when material is ready for pick-up). Regular speed requests will be filled as soon as possible (usually within 48 hours).

Use of remote access to online catalogues to check call numbers and availability of item is encouraged.

\section{PAYMENT OPTIONS}

1. Payment can be made on receipt of quarterly invoices from the University of Calgary by cheque or company VISA or MasterCard.

2. Deposit Account Option: Accounts can be pre-paid. Should you select the pre-payment option, you will receive quarterly statements as to the balance of your deposit account amount. Any monies remaining at the end of the contract year can be returned or maintained in your account for service in the following year if your company elects to renew the contract. 
